Parenting Advice and Regrets of Empty-Nesters

\author{
Ashton Chapman* \\ University of Missouri \\ David Schramm \\ Utah State University
}

*Corresponding author 


\begin{abstract}
Objective: To identify the advice and regrets empty-nest parents have when reflecting on their experiences as parents, and to investigate the utility of the parenting pyramid framework for parent education on the basis of that advice and those regrets.

Background: The parenting pyramid specifies that the parent-child relationship, teaching, and corection are key components of parenting, and that they should be emphasized in that order or priority. However, the extent to which this model is reflective of what parents actually think or do, or wish they would have done, remains unclear.

Method: Empty-nesters were recruited through social media, professional e-mail listservs, university advertising, newspaper ads in multiple states, and word of mouth, resulting in a convenience sample of 379 individuals from across the United States who completed an online, open-ended survey. Data were analyzed using thematic analysis.
\end{abstract}

Results: Consistent with the parenting pyramid, empty-nesters conveyed the importance of a healthy parent-child relationship being the foundation for teaching, reasoning, direction, and correction throughout children's lives. Empty-nesters' advice focused primarily on the importance of the parent-child relationship and the role of parents as teachers. Regrets were related to overemphasizing correction and negativity.

Conclusions: These findings provide empirical support for the utility of the parenting pyramid as a useful framework for principles-focused parent education.

Implications: The relative importance of relationship building versus correction and discipline suggest that parent educators should reduce the amount of time and attention they spend answering the question, "What to do when things go wrong?" and focus more on helping things go right.

Keywords: empty-nesters, children, parent-child relationships, parent education, qualitative research 


\section{Parenting Advice and Regrets of Empty-Nesters}

Parenting advice is widely accessible; helping professionals outline parenting best practices in books, blogs, and family scholarship. In addition, more informal sources of advice, including friends, family members, and other parents, commonly act as resources for helpseeking parents. Research reinforces the importance of quality parenting: Parenting variables account for a substantial amount of variation in child outcomes, ranging from $20 \%$ to $50 \%$ (e.g., Reiss et al. 1995). However, many existing outlets for parenting advice have been criticized for creating a dependence on professional help sources (e.g., medical or psychological professionals) and discouraging parents from relying on their own knowledge, experience, and intuition when making parenting decisions (Dolev \& Zeedyk, 2006). Existing resources also focus almost exclusively on only one aspect of childrearing — discipline - while paying far less attention to strategies that may help reduce parents' focus on correction (e.g., relationship building, teaching).

Empty-nest parents (i.e., parents whose adult children no longer coreside with them) represent one type of non-professional, yet experienced group from which parenting advice may be garnered. Research suggests that when parents are overwhelmed with parenting and related stresses, they may struggle to take others' perspectives or see the larger purpose of parenting and the happiness that is possible (Katz \& Gottman, 1997). Given that empty-nest parents are further removed from the daily hassles of childrearing, they may be well-positioned to critically reflect on their parenting histories and offer valuable insights regarding the pains and pleasures of parenting. The purpose of this qualitative study was two-fold: (a) to examine the advice and regrets empty-nest parents offer to parents who are actively parenting minor children across various stages of children's lives, and (b) to empirically investigate the utility of the parenting 
pyramid (Arbinger Institute, 1998), a guiding framework for parent edication that emphasizes parents as teachers above parents as disciplinarians for developing healthy parent-child relationships. Considered together, we wanted to explore the overlap between the advice and regrets provided by empty-nesters and the principles governing the structure of the parenting pyramid.

\section{Review of the Literature}

\section{Fundamental Components and Frameworks of Parenting}

Across decades of research, parenting scholars have come to a general consensus on the fundamental components of effective parent education. Specifically, scholarship on parenting and parent education often centers around two fundamental components related to positive outcomes: a supportive component comprised of warmth, affection, and involvement, and a controlling component that includes structure, limits, and monitoring behavior (see Barber, Stolz, and Olson, 2005, for a review). Baumrind's (1971) typological framework focuses on a balance of two very similar dimensions of parenting: responsiveness and demandingness (see also Maccoby \& Martin, 1983). The lay literature often simply refers to these dimensions as nurture and guidance, respectively. These two fundamental areas are also key components of the national extension parent education model (NEPEM), which outlines six priority parenting practices (Smith, Cudaback, Goddard, \& Myers-Walls, 1994), as well as the Texas Registry of Parent Educator Resources (ROPER), which specifies ten areas that are central to the work of parent educators (Center for Parent Education, 2004). A vast body of literature suggests that high levels of nurturing and guidance result in more positive outcomes for children. For example, Amato and Fowler (2002) found that children do best when parents spend quality time with them, support them, avoid harsh punishment (e.g., spanking), and share positive open communication. 
Another framework, the parenting pyramid (Arbinger Institute, 1998) specifies that correction, teaching, and the parent-child relationship are key components of parenting. More specifically, the framework indicates that correction is placed at the top of the pyramid (the smallest part of the pyramid), with teaching under it in the middle, and the foundation of the pyramid (the largest part) consisting of the parent-child relationship, defined as the emotional and affectionate bond between a parent and child, strengthened by love, trust, and respect (see Figure 1). The arrangement of the layers within the pyramid shape is intended to convey the interdependence of the pyramid components; that is, the effectiveness of correction depends on prior teaching, and the effectiveness of teaching depends on the quality of the parent-child relationship. Additionally, the size of each component of the pyramid is associated with its relevant importance; the parent-child relationship, for instance, is the largest and most fundamental component of the pyramid, which suggests that parents should spend most of their time and energy on nurturing a positive parent-child relationship (i.e., the foundation and largest portion of the pyramid) so children will be open to teaching and correction, when needed. Conversely, although still a critical aspect of parenting, the correction component is the smallest portion of the pyramid, suggesting that parents should invest less time here compared to strengthening the parent-child relationship. Although the amount of time and effort devoted to each area will depend on a number of factors, including developmental age, temperament, and cognitive abilities, it could be argued, as the Arbinger scholars have, that much more time and attention in the lay parenting literature (e.g., books, magazines, blogs) is devoted to discussing and disseminating information related to the top level of the pyramid, correction and discipline, rather than building the foundation of the parent-child relationship. 
The framework rests on two types of questions that parents often ask themselves and others when it comes to intervening in their children's lives. The first question is, "What do I do when things go wrong?" and can be expressed in a variety of ways (e.g., "What can we do to stop our children from fighting?" "What can we do to get our children to quit lying?"). This question focuses primarily on the top of the pyramid, which centers on punishment, correction, and discipline. The second question the parenting pyramid framework essentially asks is, "How do I help things go right?," which focuses on being proactive and positive (e.g., "What can we do to help our children be more kind to each other?" "What can we do to help our children tell the truth and be honest?"). Arbinger scholars have contended that "when asked which type of question is primary, most of us realize it is the second. But when we are asked which question we actually spend more time on, we typically say the first. . . . the key to effective parenting is to reverse this order in expenditure of time and energy" (Arbinger Institute, 1998, p. 3, emphasis in original).

Some parenting scholars have emphasized the importance of focusing less on teaching specific techniques and prescriptions for controlling and correcting children's behavior and more on demonstrating a committed warm, nurturing, caring relationship (Brazelton \& Greenspan, 2000) on the basis that "the quality of the relationship is more important than specific techniques" (Goddard, Myers-Walls, \& Lee, 2004, p. 464). Such insights are reflective of the principles included in the parenting pyramid, yet to our knowledge there have been no empirical investigations of the utility or feasibility of the application of these principles in guiding parenting beliefs and behaviors. Therefore, the question of whether the principles upon which the parenting pyramid was developed (i.e., focus on relationship-building as primary, teaching as secondary, and discipline or correction as tertiary) are reflective of what parents actually think or 
do, or wish they would have done, remains an empirical one. Given that the effectiveness of interventions or programs designed to affect beliefs and behaviors has been linked to the perceived usefulness of such efforts in real-world settings (see Spoth et al., 2013, for a review), it is equally important to understand if, how, and to what extent parents' reflections map onto parenting fraemworks such as the parenting pyramid.

\section{The Challenges, Regrets, and Rewards of Parenting}

Anecdotally, parenting is often described as the most difficult, yet most rewarding job in the world. Parents encounter numerous challenges and stresses as they invest substantial amounts of time, money, and effort into raising their children. Access to the collective wisdom and experience of empty-nest parents may help parents who are actively raising children as they manage the daily stresses associated with parenting, and a reduction in parenting-related stress may, in turn, help parents better and more consistently enjoy and appreciate the experience of parenting while still in the daily process of parenting.

Indeed, research indicates that parenting is one of the top regrets people have in life. Using a 12-category framework of life domains, Roese and Summerville (2005) conducted a meta-analysis of life regrets, including regrets of inaction (i.e., things they wished they would have said or did, but did not) as well as regrets of action (i.e., things they said or did, but now feel remorse about). Their results indicate that Americans' biggest regrets fall into the following six domains (in descending order of frequency): education, career, romance, parenting, selfimprovement, and leisure. Thus, many parents wish they would have done things differently. Interestingly, regrets involving social relationships, including parent-child relationships, tend to be more intensely felt than intrapersonal regrets such as work and education (Morrison, Epstude, 
\& Roese, 2012). But what specifically do parents regret? If they could go back and do or say things differently, what would that look like? Questions such as these have yet to be answered.

Parents are faced with numerous stressors and often feel overwhelmed by daily hassles, causing them to lose sight of the larger vision and rewards of parenting, and becoming less involved parents (Crnic, Gaze, \& Hoffman, 2005). However, empty-nest parents may, in hindsight, be able to take that larger view and reflect thoughtfully upon their parenting experiences. Gathering this wisdom from empty-nest parents who have experienced the stresses of parenting and sharing it with parents who have children at home may help normalize and even enrich parents' experiences and children's outcomes. Moreover, investigating possible links between empty-nest parents' advice and regrets and the principles presented in the parenting pyramid can improve understanding about the utility of the pyramid's principles for guiding parents' childrearing attitudes and behaviors. Thus, this study was designed to discover the advice and regrets of empty-nest parents, and to examine the extent to which that advice and those regrets align with the parenting pyramid principles. Accordingly, while informed by the parenting pyramid (Arbinger Institute, 1998), the following research questions (RQs) guided this exploratory study:

RQ1: What advice do empty-nest parents share with current parents?

RQ2: How does the advice provided by empty-nest parents differ within- and betweengroups of parents with children of different ages (0-5 years, 6-11 years, and 12-18 years)?

RQ3: What regrets do empty-nest parents have about parenting and what would they do differently? 
RQ4: How consistent are empty-nest parents' advice and regrets with the guiding principles of the parenting pyramid?

\section{Method}

\section{Sample}

Inclusion criteria required that participants be a biological parent or legal guardian (regardless of marital status) of at least one child who lived with them for a minimum of 10 years but no longer had any children living with the parent or guardian and the youngest child was at least 17 years of age. Parents were recruited through social media, professional e-mail listservs, university advertising, newspaper ads in multiple states, and word of mouth. As an incentive for participation, eligible participants who completed the survey were entered into a random drawing to win one of ten $\$ 20$ gift cards to Walmart. These proceedures resulted in a convenience sample of 379 empty-nest parents from across the United States. Parents ranged in age from 42 to 81 years $(M=54.3, S D=13.6)$, reported having between 1 and 6 children $(M=2.6, S D=1.7)$, and had been empty-nesters for 1 to 26 years $(M=6.13, S D=4.0)$. At the time of data collection, $65.7 \%$ of parents reported being in their first marriage, $14.7 \%$ were remarried, $11.2 \%$ were single, and less than $1 \%$ self-identified as cohabiting with a romantic partner. Participants were primarily White (90\%), female (78\%) and college-educated (71\%).

\section{Procedure}

Data were primarily gathered online via SurveyMonkey. First, parents contacted a member of the research team to express interest. Next, eligible parents were sent a link to an online survey, where they were presented with open-ended prompts designed to elicit their advice to hypothetical parents with children in each of the following age groups: birth to 5 years, 6-11 years, and 12-18 years. The advice prompts were, "Knowing what you know from your 
experience as a parent, what advice would you give to parents of . . :" followed by prompts for each age group. In addition to providing advice to other parents, participants were also given the opportunity to respond to the following question related to possible regrets:

Looking back, it is common for most parents to have a few regrets, or wish they had done a few things differently if they could do it all over again. If you could go back, what do you wish you could do differently?

\section{Analysis}

Researchers reviewed and analyzed written responses acquired from the open-ended survey responses provided by 379 empty-nest parents using thematic analysis. Dedoose, an internet-based programmatic tool intended for use with qualitative data, facilitated data analysis. Because participants provided advice to hypothetical parents with children in each of the three age groups, a total of 1,137 responses (379 participants x 3 sets of advice) were reviewed. Thematic analysis began with the creation of a codebook using inductive coding procedures (Corbin \& Strauss, 2008; Nowell, Norris, White, \& Moules, 2017). Line-by-line coding of survey responses and interview transcripts resulted in 117 initial codes. We then analyzed the advice specific to each age cohort. Within responses directed toward parents with children 0-5 years of age, 70 codes were applied a total of 1,284 times $(M=3.4$ codes per respondent); for ages 6-11 years, 107 codes were applied 2,003 times $(M=5.3$ codes per respondent); and for ages $12-18$ years, 82 codes were applied 1,671 times $(M=4.4$ codes per respondent $)$. As these numbers suggest, not all of the original 117 codes were applied within each age-cohort.

Examples of initial codes included stick to the rules, don't back down, and follow through with punishment. Next, we reviewed the initial codes and consolidated these codes into related categories (i.e., axial coding; Corbin \& Strauss, 2008). For instance, the initial codes listed above 
were combined into a category (or larger axial code) of be consistent with discipline. Examples of other axial codes included: communicate with kids, give quality time, be involved in kids' lives, and love kids unconditionally. A total of 31 axial codes emerged from initial code consolidation. The first author then re-read all open-ended responses and coded each response using the axial codes generated through initial code consoliation. To achieve greater parsimony, axial codes were only retained if they represented at least $10 \%$ of the written responses within a given age group. This cutoff has been used in comparable studies (e.g., Ganong, Jamison, \& Chapman, 2015). Consistent with the goals of the present study, axial codes were then organized into larger themes in accordance with the three core concepts of the parenting pyramid: parentchild relationship, teaching, and correction (Arbinger Institute, 1998). As a final analytic step, we compared advice codes assigned across all three age groups and created a list of the most common advice given. See Table 1 for a summary of axial codes and their prevalence within the data.

\section{Results}

Consistent with the parenting pyramid, empty-nesters in our study conveyed the importance of a healthy parent-child relationship being the foundation for teaching, reasoning, direction, and correction throughout children's lives. The empty-nest parents' advice and regrets suggested that positive, emotionally close, and supportive parent-child relationships may help parents be better teachers, and ultimately reduce parent stresses related to discipline and correction. Advice and regrets provided by empty-nest parents consistently matched the principles outlined in the parenting pyramid (Arbinger Institute, 1998). We describe the overlap between the advice and regrets of empty-nesters with the parenting pyramid's fundamental 
principles (i.e., findings related to our fourth research question) while answering our first three research questions.

\section{RQ1: General Parenting Advice}

Irregardless of child age, empty-nest parents perceived that parents should (a) be consistent with discipline; (b) communicate with children; (c) give quality time; (d) be actively involved in children's lives (e.g., engage in monitoring); (e) love children unconditionally; (f) be actively involved in children's education (e.g., engage with teachers, assist with homework); (g) read to children; (h) provide consistency in the structure and routine of children's lives; (i) teach responsibility; and (j) encourage exploration. These ideas emerged consistently and frequently in empty-nesters' responses; that is, they represent advice that empty-nesters perceived as important for all parents, regardless of the ages of their children. Using the parenting pyramid (Arbinger Institute, 1998) as a guide, the emergent categories (i.e., axial codes) for overall parenting advice are grouped and discussed below in accordance with each level of the pyramid: parent-child relationship, teaching, and correction.

Relationship-focused advice. Empty-nest parents advocated for parents with children of all ages to build relationships with their children. Relationship building was described as parents' most important, and most rewarding, job. Specifically, empty-nest parents advised current parents to communicate with kids (249 code applications), spend quality time with kids (238 code applications), be involved in kids' lives (by getting to know their interests, dreams, friends, etc.; 210 code applications), love kids unconditionally (160 code applications), and be involved in kids' schooling (by getting to know their teachers, assisting with and showing interest in schoolrelated activities, etc.; 158 code applications). Considered together, relationship-focused codes, which are focused on building the foundation of the parenting pyramid, were present in over 
$84 \%$ of participants' responses (1,015 code applicantions out of 1,196 total responses). Advice regarding how to build the parent-child relationship took many forms, but the underlying message was the same: The strength and quality of parent-child relationships were perceived as the cornerstones upon which all other facets of parenting rested. Without a solid relationship, empty-nesters often stated that parents' abilities to teach and discipline children would be fraught with challenges. One empty-nester summed up the importance of the parent-child relationship well when saying, "By remaining involved, you maintain their respect over the long haul, and despite what they say in the moment, they will ultimately agree that your interest and caring made a big difference."

Teaching-focused advice. Empty-nest parents also saw immense value in the role of parents as teachers. Specifically, empty-nesters encouraged parents to teach important life skills, two of which were literacy through reading (136 code applications) and work ethic and independence through responsibility (128 code applications). Empty-nesters also advised parents to teach children the value of lifelong learning by means of encouraging exploration (124 code applications), both in regard to children's own identities and their social worlds. Teachingfocused codes, which represent the middle portion of the pyramid, were present in $32 \%$ of empty-nesters' responses (388 code applications out of 1,196 responses). Participants saw teaching as something secondary to relationship-building; although it was considered important, empty-nesters described it as unlikely to occur in the absence of a positive parent-child relationship. One participant reiterated this message by sharing:

Encourage them - be the cheerleader, not the referee. Teach them-model all that is good and responsible. Set a good example — teach responsibility, self-discipline, self-respect, 
gratitude, compassion, forgiveness, and the like by applying it in your own life. You will soon reap what you sowed earlier in their [the children's] lives.

Correction-focused advice. Empty-nesters also advised parents to be consistent in their routines (133), particularly in regard to disciplinary practices (250). Correction-focused codes were present in $32 \%$ of participants' responses (383 codes out of 1,196 excerpts). Although a necessary part of parenting, correction was no more common of a concern among these emptynesters than teaching. From their perspective, when relationships with children were positive, and parents were able to serve as skilled teachers, the need for children to be corrected and redirected lessened. When advice related to correction was provided, empty-nesters often reiterated the importance of the parent-child relationship and the parent's role as teacher. In fact, many empty-nesters perceived teaching and correction as synergistic, suggesting that correction was not simply a way to reduce undesired behavior through discipline, but also a way to promote more desirable behavior through teaching. For example, one participant stated:

This is where staying consistent pays off. Set boundaries that have been jointly decided upon by you and your children. When disciplining your children, it's important to hold them accountable so they will learn to be responsible. Discipline is more than just punishment for bad behavior. Continue to share special moments and create times to bond with your children and teach them new lessons, even in hard times.

\section{RQ2: Age-Specific Advice}

The more general parenting advice was derived from advice that was common across age groups, but empty-nesters also shared some age-specific advice that they felt was more appropriate and relatable to children of particular ages. Reflecting on their own experiences and accrued knowledge about child development, empty-nesters were able to tailor their advice to the 
specific challenges and joys that each developmental period brings. Moreover, retrospective reports allowed empty-nesters to consider the ways in which their approaches to childrearing (including their struggles, successes, and failures) changed as children aged. Specifically, emptynest parents provided advice to parents with children under 5 years of age, 6-11 years of age, and 12-18 years of age. Again, findings from the age-specific analyses revealed that parents focused primarily on the importance of relationship-building, followed by teaching and correction.

Ages birth to 5 years. With regard to children under 6 years of age, empty-nest parents advised parents to focus first and foremost on their relationships with children, as evidenced by their encouragement to enjoy the moment, engage in active play with children, and exercise patience. Respondents commonly advocated for parents to enjoy the moments shared with their children, with advice such as "Enjoy this stage of life—it doesn't last" and "They grow up too fast - take time to enjoy them." One way empty-nesters advocated for parents to enjoy time with their young children was to engage in active play with them. In fact, playing with kids emerged as a central axial code only for this age group. Consistent with the parenting pyramid (Arbinger Institute, 1998), advice regarding play centered around the importance of parent-child interaction and child-centered learning. One participant advised, "Make time to relax, play, and enjoy your young children—nothing else is more important." Although empty-nesters commonly emphasized the importance of joy and play, they also recognized the challenges that life with small children can bring. As such, parents with children under 6 years of age were advised to be patient. Patience was encouraged in many different forms, although patience with developmental growth and milestones and patience regarding day-to-day struggles were most common. For example, one respondent shared, "At this point in time your child is physically demanding, but 
you are young and are capable. Patience is an important quality to foster at this time." Another advised, "Don't wish time away and enjoy every moment and stage your child is going through. There are life lessons and life skills that can be learned at each stage.”

Ages 6 to 11 years. For children 6-11 years old, respondents advised parents to praise children regularly and promote positive identity development. Such advice was illustrative of parents' focus on teaching, which they perceived as secondary to earlier foundations of relationship-building encouraged during children's earliest years (birth to age 5). Empty-nesters recognized the importance of helping children explore their interests, likes and dislikes, and individual personalities, particularly at this stage in children's development; such exploration was perceived as central to helping kids develop socially, emotionally, and personally. In line with empty-nesters' emphasis on promoting positive identity development, one participant encouraged parents to, "Let your children follow their own interests and do not try to form them into what you or society thinks they should be." Another wrote, "Let life happen, don't plan and push for what you feel your child should do and be." Building children's confidence through praise was also cited as an important cornerstone for identity development in this age group. Praising children was commonly regarded as an ideal way to boost children's self-concept and self-esteem, and to demonstrate parents' supportiveness. For example, one parent advised, "Give them lots of encouragement and love. Help them to have a positive personality, and reward them for milestones; it builds self confidence." Another participant echoed this, "This is a very impressionable stage in a child's life. What they see and hear - they remember. Praise themthis builds confidence."

Ages 12 to 18 years. For children 12-18 years of age, empty-nest parents advised parents to do more listening than talking; set clear boundaries for behavior; let children make mistakes; 
and be a parent, not a friend. Here, empty-nest parents relied on previous philosophies of relationship-building and teaching, but also acknowledged occasional need for correction. Respondents often regarded the adolescent years as a time to temper boundary setting with children's increasing independence, even if that meant allowing children to make mistakes along the path to adulthood. Such advice was illustrative of relationship-building efforts parents engaged in when children were young that now served as the foundations for setting loving yet firm boundaries for children later on. For example, one parent stated, "Know when to back off and let them grow. Help them finish the task of becoming independent from you but still be part of your family." Others agreed, advising parents of teens to: "Be involved in everything they will let you be a part of while encouraging them to become independent;" "Stay in charge but share the power so they can become their own adults;" "Cheer them on and push them when they need it. It is a balancing act between holding on and letting go;" "Don't back down. Their job is to become independent so they will fight your protective attempts. You be the one to manage the fine line of freedom versus protection. Stay involved, but don't smother. Give them roots and wings," and "Balance letting go with enforcing boundaries. Fight only the battles that are important. Give them space to be the person they are meant to become. Focus on safety and positive character, not the details."

Allowing kids to make mistakes was perceived as a way for teenagers to learn responsibility and practice independence; respondents advocated for allowing teens to make mistakes and experience consequences before launching from the nest. One parent advised, "Learn how to encourage without doing it for them. Teach them to be critical thinkers - think through situations and discuss the choice and consequences with them then let them make the choice and experience the consequences." Others applauded parents for making it this far and 
encouraged them by saying, "Congratulations, the easy part is over. Your job now is to encourage independent decision-making. Your child must be allowed to fail, to take responsibility for actions, and take the consequences." Other advice included, "Remain close and involved but allow them to make mistakes and learn from them. Provide guidance without control. Think ahead to young adulthood and what skills will be needed when leaving the nest. Prepare them," and "Teach them to make good decisions and support them when they do . . . help brush them off and deal with the consequences when they don't. Be there for them, but don't save them from consequences that will teach them important life lessons."

Empty-nest parents also encouraged parents of teenagers to listen to kids, as part of an open-model of communication, but to ensure that parent-child boundaries remained clearbeing a parent, not a friend was common advice. Advice related to listening included, "Be ready to be an ear, anytime, anywhere," and "Be open to all conversations. Listen without jumping in with your advice. Your child may just need someone to listen, not necessarily solve the problem." Respondents indicated that listening to teenagers is an important opportunity for bonding, but advice related to listening was almost always followed up with warnings about moving into the "friend zone" with children. Empty-nesters strongly encouraged parents to maintain authority in the lives of their growing children, particularly in regard to discipline and boundary setting. One parent advised, “Always remain the parent. Don't try to be their best friend; they have friends." Others wrote, "You are doing your job as a parent only if you make them mad at you once in awhile," and "Be a parent first and a friend second." Consistent with the general parenting advice, the age-specific advice provided by empty-nesters aligned with the key tenets of the parenting pyramid (Arbinger Institute, 1998). The majority of this advice could be 
categorized as relationship-focused, followed by a teaching focus, then an emphasis on correction or discipline.

\section{RQ3: Regrets}

Of the 397 participants, $291(73 \%)$ provided at least one parenting regret. When regrets were present in empty-nesters' responses, the type of regret was coded into one of four categories: correction, teaching, parent-child relationship, and other/personal. Consistent with our research purpose, we selected these categories based on the parenting pyramid (Arbinger Institute, 1998), which allowed for us to draw comparisons between parents' advice and regrets and the pyramid's principles. In an effort to capture within-group variability for each category, codes reflected whether participants regretted having too much or too little emphasis on correction, teaching, the parent-child relationship, or other/personal (e.g., relationship with a romantic partner, amount of time spent working) while actively raising children. A total of 76 parents $(26 \%)$ reported a regret related to correction. Some respondents believed they had been too lenient (7\%), but far more empty-nesters regreted being too harsh and impatient (20\%). As an example of being too lenient, one empty-nest parent said, "I wish I would have set stricter boundaries for punishment when my kids acted up." Other parents, regretting that they were too harsh mentioned things such as "I wish I would have been less harsh with discipline," "I wish I'd not shamed the children when they were younger," and "I wish I would not have yelled at them. You can get angry without screaming."

Another category of regret, teaching, was mentioned by nearly one-fourth (23\%) of respondents. Empty-nest parents only regretted doing too little teaching, never too much. For example, regrets ranged from a lack of teaching children how to manage stress and anxiety, to teaching them practical household responsibilities such as cleaning and cooking, and even 
teaching them about their faith and values. One empty-nest parent said, "I wish I would've taught my daughter how to cook basic meals and do basic household chores and wash clothes." Another wrote, "I think that I would have offered more opportunities to do more activities that involved physical activities, such as canoeing, more hiking, etc.” And yet another parent wrote, "I would have purposefully brought peers and teachers into their lives that would encourage them to greatness."

A third category of regrets, related to the parent-child relationship, was felt by $53 \%$ of the empty-nest parents. The majority of these regrets were related to parents' desires to spend more time with their children and attend their school and extracurricular activities. Similar to regrets related to teaching, empty-nest parents only reported regrets about not doing enough to build the parent-child relationship; none stated that they regretted focusing too much on relationship-building. For example, one parent wrote, "I often missed some of my older children's activities because I had younger ones at home. I wish now I would have made more of an effort to be more involved with their activities." Another parent wrote, "I wish that I would have listened with my full attention each time the children wanted to talk." Feeling like her family missed out on time together, one parent mentioned, "I wish we would have taken more family vacations or participated in activities together." Finally, one empty-nest parent wished she would have changed her priorities: "I would let myself have more fun and forget some of the things that seemed important at the time."

There were some regrets that we categorized as other/personal. These regrets varied dramatically accross participants, ranging from saving money for their children for college, to working on their marriage relationship for their kids. One parent wrote, "I wish I had all of the great parenting resources that exist today and had absorbed it all well enough to recognize some 
things that I missed." Another wrote, "I would have been more assertive with my children's schools, and would have asked for help from my friends and church more." Other parents wished they would have relaxed more and not worried so much (e.g., "I wish I would have relaxed, had more fun and enjoyed them more").

\section{Discussion and Implications}

Most parenting education frameworks rest on two fundamental components: a supportive and nurturing component that emphasizes warmth, affection, and involvement, and a controlling component that includes structure, limits, and discipline (Barber et al., 2005). Historically, these two components have not been given equal weight and emphasis, with most parenting advice from books, blogs, and popular parent education curricula focusing on methods of correction and punishment. The results of the present study suggest a better balance between the support and control components of parenting may be needed, and provides support for an existing but underinvestigated framework - the parenting pyramid (Arbinger Institute, 1998) — that may serve as a useful guide for parents and parent educators. Indeed, $84 \%$ of participants' responses mentioned ideas related to strengthening the parent-child relationship, and 32\% commented on topics related to teaching and $32 \%$ mentioned advice related to correction. Consistent with the parenting pyramid framework (Arbinger Institute, 1998), our results suggest that the effectiveness and frequency of correction depends on the amount and quality of teaching a parent provides, which in turn depends on the quality of the parent-child relationship. As the pyramid implies, parents saw the pyramid components as interdependent; that is, parents commonly regarded correction not as an isolated opportunity to reduce negative or unwanted behavior, but also as an opportunity to teach children by sharing or modeling more desirable behavior. 
Empty-nest parents had much advice to offer parents; some also expressed regrets. Researchers and practitioners can use empty-nesters' insights to meaningfully inform parent educators. Using the parenting pyramid as a framework to interpret the findings, contrary to popular programs and parenting books, we recommend parent educators invest more (or at least equal) time emphasizing the importance of building and maintaining the parent-child relationship so children will be more open to teaching and correction. We echo past calls of parenting scholars who propose that "the challenge for the parent education field is developing and refining strategies for encouraging [strong] parent-child relationships" (Goddard et al., 2004, p. 464). Many parent education programs focus primarily on the top level of the pyramid, correction, which centers on "what to do when things go wrong" rather than strengthening the parent-child relationship, which centers on "how to help things go right." Correction and discipline are a vital component of the parenting pyramid; of the responses focused on correction and discipline (27\%), the bulk of the advice shared is to be consistent with discipline, and emptynesters perceived that to be easier to acomplish when there is a healthy parent-child relationship and parents embrace their role as teachers. In line with these ideologies, empty-nest parents' regrets could be summarized this way: more patience, less harshness. Interestingly, when asked about their advice for children of different ages, empty-nest parents' responses largely centered on principles rather than specific skills, techniques, or prescriptions for success. For example, they were much more likely to mention something like, "be consistent with discipline" rather than "use timeout for hitting," or "spend quality time with them" rather than "take 15 minutes every night to talk with your teenager." Therefore, we encourage parent educators to spend more time and effort with parents encouraging the building of healthy parent-child relationships and teaching children, and less time on specific methods of correction and discipline. We also 
advocate that parenting educators invest more time teaching parenting principles (e.g., see NEPEM framework, Smith et al., 1994), than providing prescriptive phrases, skills, and specific techniques for parenting.

For young children (under 6 years of age), the advice from empty-nest parents implies that parent educators should emphasize enjoying the moment and each stage of development and growth, which passes quickly. Investing large quantities of time playing with, reading to, and teaching children is paramount to creating a positive attachment, as is the importance of having patience with young children while they are learning about countless areas of life. Routine, consistency, and structure were also central themes in the advice given from empty-nest parents. Some empty-nest parents also mentioned the importance of seeking out and learning helpful strategies for correction from books or classes, which many empty-nesters perceived to be more plentiful and accessible compared to when they were young parents. At this stage, teaching and discipline often are inseparable, so emphasizing strategies for and the importance of interweaving direction and correction is essential.

For children between 6 and 11 years of age, the advice and regrets from empty-nest parents centered on the development of children's identity, and suggest that parent educators should emphasize the importance of allowing children to explore interests and activities while still teaching responsibility. To strengthen the parent-child relationship, empty-nesters recommended specific praise for effort, encouragement, monitoring, and being involved in their various activities, including engagement with teachers and helping with homework.

Following the advice from empty-nest parents with regard to teenagers, parent educators may do well to help parents understand the importance of providing high levels of nurturing, and balancing that with establishing fewer (compared to none or many and extreme) rules related to 
setting limits and consequences. Another principle that parent educators can reinforce is the importance of reasoning with adolescents - examining causes and consequences, actions and likely outcomes, principles and practices. Empty-nesters encouraged parents to reason with teenagers about responsibilities and rules, including the "why" of parental involvement in their lives, which may help teens be more likely to respect and be responsive to the rules.

Our results suggest that the parenting pyramid framework may be useful for parents as they engage in the challenges and joys of parenting to the extent that it helps them prioritize time spent with children across the domains of relationship-building, teaching, and correction. We note, however, that our findings also suggest the most effective balance of these three areas of parenting may depend on factors such as children's ages and stages of development, personality, temperament, and emotional or mental maturity and well-being. Even children within the same family may benefit from different amounts of discipline, teaching, and nurturing. In short, our data suggest that the amount of time and effort parents invest in the three areas should be tailored for individual children and circumstances. Thus, interpreting the parenting pyramid slices by the relative size or weight is less important than interpreting what individual children need from a loving parent or caregiver.

\section{Limitations and Future Directions}

Exploring the advice and regrets of empty-nest parents provides a unique contribution to existing bodies of research, but our investigation is not without limitations. First, our findings are based largely on the experiences of White, educated, middle- to upper-class empty-nest mothers and researchers, educators, and practitioners should therefore use caution when generalizing these findings to larger populations. Although the parents in our sample were not immune to parenting stressors and regrets, their relatively high levels of education and income, as well as 
their access to social supports (e.g., many of our participants were in romantic partnerships), may have afforded them opportunities to manage parenting stressors in ways that differ from parents with fewer resources. Moreover, the relative privilege of the parents in our study may have also allowed them more choice in whether, and to what extent, they participated in their children's lives. Given the explorative nature of our study, however, it is important to note that generalizability to populations is not the goal of qualitative research. Rather, qualitative methods serve to illuminate complexities of particular phenomenon (Corbin \& Strauss, 2008) - in this case, advice and regrets of empty-nest parents and their alignment with principles guiding the parenting pyramid. It is our hope that this study sheds light on the nuances of parenting beliefs and behaviors, particularly as they relate to relationship-building, teaching, and discipline/correction, and that such knowledge may then be applied to parenting-specific theory and practice.

Another caution when interpreting and applying these results is related to possible differences between cohorts of parents. For instance, it is likely that some parents with minoraged children still living at home may discount the advice and regrets provided by older generations of parents given differences in the resources available (e.g., technology) to parents across different decades and parenting norms derived through social perceptions of parenting (e.g., acceptability of corporal punishment as a form of correction). These biases must be recognized by parent educators when discussing these research findings. They may be overcome by helping parents develop positive life philosophies related to parenting by asking parents to think about the big picture of parenting; what type of relationships do they want with their children, what is challenging about parenting, and what they ultimately want for their children. Having a better understanding of what parents envision for their children, and pointing out that 
historically, most parents have desired similar outcomes and relationships, may invite parents to be more open to advice and regrets from empty-nest parents, with whom they may share more similarities than differences.

It is also noteworthy to consider how parents' socioeconomic status may influence the types and sources of parenting advice sought. For instance, reliance on formal sources of parenting advice (e.g., as provided by books) may be specific to a certain segment of educated middle-class parents, whereas reliance on informal sources of parenting advice such as family and friends may be preferred by a broader, more diverse cross-section of parents. Nevertheless, we believe findings from our study may be useful for all parents, as the principles-based approach that was commonly advocated for by empty-nesters (and further supported by the parenting pyramid) appears to confer a consistent, yet variable framework for advice that may be useful in both informal and formal parent education efforts. Parent educators can point out that all parents experience stress and encounter challenges with children-there are no perfect parents. Normalizing the joys and stresses of parenting may prevent parents from feeling guilt about not having as much time as they would like to strengthen the relationship with their child(ren) and help empower them to prioritize the time they do have with children to focus on relationship-building and teaching, which, in turn, is likely to limit time spent on correction. Moreover, parent educators can describe a variety of parenting principles and practices and invite parents to apply ones that may work best in their situations, or adapt them to meet their needs.

Looking to the future and considering how the findings from this research might inform prospective studies and parenting practices, we reflect on some of the key findings and unexpected outcomes. First, after coding the empty-nest parents' comments we observed that statements about correction were just as common as teaching. After examining what we coded as 
the most consistent piece of parenting advice, "be consistent with discipline," we believe that this has substantial overlap with the idea of teaching. Being consistent with discipline and routines may be viewed as important because it teaches children that parents are concerned enough about them that they want to guide them in paths that will set them up for success. Inconsistent discipline may be confusing for children, but consistency teaches them that certain behaviors lead to certain outcomes and consequences, which helps shape whether children will repeat behaviors in the future. The words "discipline" and "correction" can be understood by some to mean training or teaching someone to obey rules or to show them the correct way to behave, whereas punishment may be a form of correction parents use, but little learning may come from it. Furthermore, the parenting pyramid framework may be helpful for parents and practitioners as an idea that may lead to a better balance in time and energy, without prescribing or overemphasizing proportions and weight given to each slice. The overarching principle is this: children will be more open to teaching and correction when they feel loved, supported, and appreciated.

Future studies could explore the levels of the pyramid and how much time and energy parents invest in each level. For example, adolescents could be asked to estimate what percent of each parent's time and energy is devoted to each level of the pyramid. The results may be revealing for parents and may promote a reorganization of priorities. Similarly, practitioners may reevaluate how much they emphasize each level of the pyramid in the programs they offer, and emphasize the importance of establishing and maintaining a positive parent-child relationship as foundational, regardless of the specific type of correction or discipline that is used.

Future research could also explore parenting advice using a variety of methods, including cross-sectionally and longitudinally. The data presented here are based on retrospective reports; 
that is, we asked parents to reflect on the collective histories of their parenting practices. It is possible that parents' recollections of their childrearing practices may have been skewed, as studies have shown discrepancies in retrospective memory with older adults (Henry, MacLeod, Phillips, \& Crawford, 2004). Furthermore, a negativity bias exists for most people, which suggests that negative experiences exert a larger impact on human brains than positive experiences of the same magnitude (Ito, Larsen, Smith, \& Cacioppo, 1998). This indicats that parents may be more likely to remember, regret, and report events and experiences related to correction and harshness more easily than the day-to-day nurturing experiences of parenting.

Future research comparing advice and regrets from current parents, as well as empty-nest parents, would allow for corroboration of parenting advice provided at different points in the family life cycle. Longitudinal data would provide additional insight into the types of advice and experiences of regret empty-nest parents share as they themselves age. Additionally, future research should examine the disconnect between what many current and empty-nest parents recommend and say and what they actually do as parents. It is imperative to explore ways of bridging the advice given by empty-nest parents (e.g. relationship building, quality time) to active application in the lives of parents with children living at home.

\section{Conclusion}

Parenting is both a challenging and rewarding undertaking. Countless outlets provide self-help information and advice on parenting, but the experiences of empty-nest parents themselves, who have launched children and had time to reflect on their years of active parenting, have typically not been widely represented in that body of knowledge. In this study, we sought to capture their guidance and regrets using the parenting pyramid framework, which emphasizes the importance of investing time and energy into building the parent-child 
relationship as a foundation for successful teaching and correction. On the whole, empty-nest parents tended to regret spending so much time on correction and displine (the top of the parenting pyramid) and advised parents to spend more time enjoying, building, and strengthening the parent-child relationship (the bottom, or foundation, of the parenting pyramid). The relative importance of relationship building versus correction and discipline depicted in these data provided empirical support for the parenting pyramid as a framework for parent education. Accordingly, parent educators are encouraged to reduce the amount of time and attention they spend answering the question, "What to do when things go wrong?" in favor of informing parents how to help things go right. 


\section{References}

Amato, P. R., \& Fowler, F. (2002). Parenting practices, child adjustment, and family diversity. Journal of Marriage and Family, 64, 703-716. doi:10.1111/j.1741-3737.2002.00703.x

Arbinger (1998). The parenting pyramid. The Arbinger Institute. Retrieved from http://www.arbinger.com/downloads/parenting_pyramid.pdf

Barber, B. K., Stolz, H. E., \& Olsen, J. A. (2005). Parental support, behavioral control, and psychological control: Assessing relevance across time, method, and culture. Monographs of the Society for Research in Child Development, 70(4), 1-137.

Baumrind, D. (1971). Current patterns of parental authority. Developmental Psychology, 4, 1103. doi:10.1037/h0030372

Brazelton, T. B., \& Greenspan, S. I. (2000). The irreducible needs of children: What every child must have to grow, learn, and flourish. Cambridge, MA: Perseus.

Center for Parent Education. (2004). Core knowledge for parent educators and professionals who work with families. Denton, TX: University of North Texas. Retrieved from http://www.coe.unt.edu/cpe/core-attitudes

Corbin J., \& Strauss A. (2008). Basics of qualitative research ( $3^{\text {rd }}$ ed). Los Angeles, CA: Sage.

Crnic, K. A., Gaze, C., \& Hoffman, C. (2005). Cumulative parenting stress across the preschool period: Relations to maternal parenting and child behaviour at age 5. Infant and Child Development, 14, 117-132. doi:10.1002/icd.384

DeVries, H. M., Kerrick, S., \& Oetinger, M. J. (2007). Satisfaction and regrets of midlife parents: A qualitative analysis. Journal of Adult Development, 14, 6-15. doi:10.1007/s10804-007-9024-5 
Dolev, R., \& Zeedyk, M. S. (2006). How to be a good parent in bad times: Constructing parenting advice about terrorism. Child: Care, Health and Development, 32, 467-76.

Ganong, L., Jamison, T., \& Chapman, A. (2015). Assessing differences in intimate partner obligations based on relationship status, gender, and parental status. Journal of Social and Personal Relationships, 32, 1-25. doi:10.1177/0265407515605665

Glaser, D. (2000). Child abuse and neglect and the brain-A review. Journal of Child Psychology and Psychiatry, 41, 97-116.

Goddard, H. W., Myers-Walls, J. A., \& Lee, T. R. (2004). Parenting: Have we arrived? Or do we continue the journey? Family and Consumer Sciences Research Journal, 33, 457-474. doi:10.1177/1077727X04266689

Henry, J. D., MacLeod, M. S., Phillips, L. H., \& Crawford, J. R. (2004). A meta-analytic review of prospective memory and aging. Psychology and Aging, 19, 27-39. doi:10.1037/08827974.19.1.27

Ito, T. A., Larsen, J. T., Smith, N. K., \& Cacioppo, J. T. (1998). Negative information weighs more heavily on the brain: The negativity bias in evaluative categorizations. Journal of Personality and Social Psychology, 75, 887-900. doi:10.1037/0022-3514.75.4.887

Katz, L. F., \& Gottman, J. M. (1997). Buffering children from marital conflict and dissolution. Journal of Clinical Child Psychology, 26, 157-171. doi:10.1207/s15374424jccp2602_4

Lou, C., Anthony, E. K., Stone, S., Vu, C. M., \& Austin, M. J. (2008). Assessing child and youth well-being: Implications for child welfare practice. Journal of Evidence-Based Social Work, 5, 91-133. doi:10.1300/J394v05n01_05

Maccoby, E. E., \& Martin, J. A. (1983). Socialization in the context of the family: Parent child interaction. In E. M. Hetherington (Ed.), Handbook of child psychology: Vol. 4. 
Socialization, personality, and social development $\left(4^{\text {th }}\right.$ ed., pp. 1-101). New York, NY: John Wiley.

Morrison, M., Epstude, K., \& Roese, N. J. (2012). Life regrets and the need to belong. Social Psychological \& Personality Science, 3, 675-681. doi:10.1177/1948550611435137

Nowell, L. S., Norries, J. M., White, D. E., \& Moules, N. J. (2017). Thematic analysis: Striving to meet the trustworthiness criteria. International Journal of Qualitative Methods, 16, 113. doi: $10.1177 / 1609406917733847$

Reiss, D., Hetherington, E. M., Plomin, R., Howe, G. W., Simmens, S. J., Henderson, S. H. . . Law, T. (1995) Genetic questions for environmental studies: differential parenting and psychopathology in adolescence. Archives of General Psychiatry, 52, 925-936. doi:10.1001/archpsyc.1995.03950230039007

Roese, N. J., \& Summerville, A. (2005). What we regret most . . . and why. Personality and Social Psychology Bulletin, 31, 1273-1285. doi:10.1177/0146167205274693

Smith, C. A., Cudaback, D., Goddard, H. W., \& Myers-Walls, J. A. (1994). National Extension Parent Education Model. Manhattan, KS: Kansas Cooperative Extension Service.

Spoth, R., Rohrbach, L. A., Greenberg, M., Leaf, P., Brown, C. H., Fagan, A. . . Hawkins, J. D. (2013). Addressing core challenges for the next generation of Type 2 translation research and systems: The translation to population impact (TSci Impact) framework. Prevention Science, 14, 319-351. doi:10.1007/s11121-012-0362-6 
Table 1

Prevelance of Axial Codes for Empty-nesters' Parenting Advice Overall and Within Development Age Groups

\begin{tabular}{|c|c|c|c|c|c|c|c|c|}
\hline & \multicolumn{2}{|c|}{$0-5$ years } & \multicolumn{2}{|c|}{$6-11$ years } & \multicolumn{2}{|c|}{$12-18$ years } & \multicolumn{2}{|c|}{ Total } \\
\hline & $n$ & $\%$ & $n$ & $\%$ & $n$ & $\%$ & $n$ & $\%$ \\
\hline Be consistent with discipline ${ }^{a}$ & 97 & 26 & 72 & 19 & 136 & 36 & 305 & 27 \\
\hline Communicate with kids ${ }^{\mathrm{a}}$ & 40 & 11 & 71 & 19 & 138 & 36 & 249 & 22 \\
\hline Give quality time ${ }^{\mathrm{a}}$ & 102 & 27 & 79 & 21 & 57 & 15 & 238 & 21 \\
\hline Be involved in kids' lives ${ }^{a}$ & 26 & 7 & 95 & 25 & 89 & 23 & 210 & 18 \\
\hline Love kids unconditionally ${ }^{\mathrm{a}}$ & 63 & 17 & 31 & 8 & 66 & 17 & 160 & 14 \\
\hline Be involved in kids' education ${ }^{\mathrm{a}}$ & 4 & 1 & 107 & 28 & 47 & 12 & 158 & 14 \\
\hline Teach responsibility ${ }^{\mathrm{a}}$ & 51 & 13 & 51 & 13 & 53 & 14 & 155 & 14 \\
\hline Read to kids ${ }^{\mathrm{a}}$ & 91 & 24 & 41 & 11 & 4 & 1 & 133 & 12 \\
\hline Be consistent with routine ${ }^{a}$ & 55 & 15 & 48 & 13 & 30 & 8 & 133 & 12 \\
\hline Encourage exploration ${ }^{\mathrm{a}}$ & 44 & 12 & 63 & 17 & 17 & 4 & 124 & 11 \\
\hline Enjoy the moment & 83 & 22 & 21 & 5 & 8 & 2 & 112 & 9 \\
\hline Play with kids & 55 & 15 & 24 & 6 & 4 & 1 & 83 & 7 \\
\hline Exercise patience & 42 & 11 & 25 & 6 & 20 & 5 & 87 & 7 \\
\hline Praise children & 17 & 4 & 42 & 11 & 19 & 5 & 78 & 7 \\
\hline Foster identity development & 0 & 0 & 51 & 13 & 37 & 9 & 88 & 7 \\
\hline Do more listening & 10 & 3 & 28 & 7 & 72 & 19 & 110 & 9 \\
\hline Set clear boundaries & 0 & 0 & 0 & 0 & 69 & 18 & 69 & 6 \\
\hline Let kids make mistakes & 5 & 1 & 28 & 7 & 53 & 14 & 86 & 7 \\
\hline Be a parent, not a friend & 12 & 3 & 12 & 3 & 48 & 13 & 72 & 6 \\
\hline
\end{tabular}

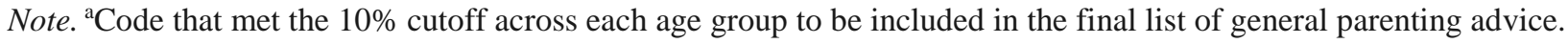




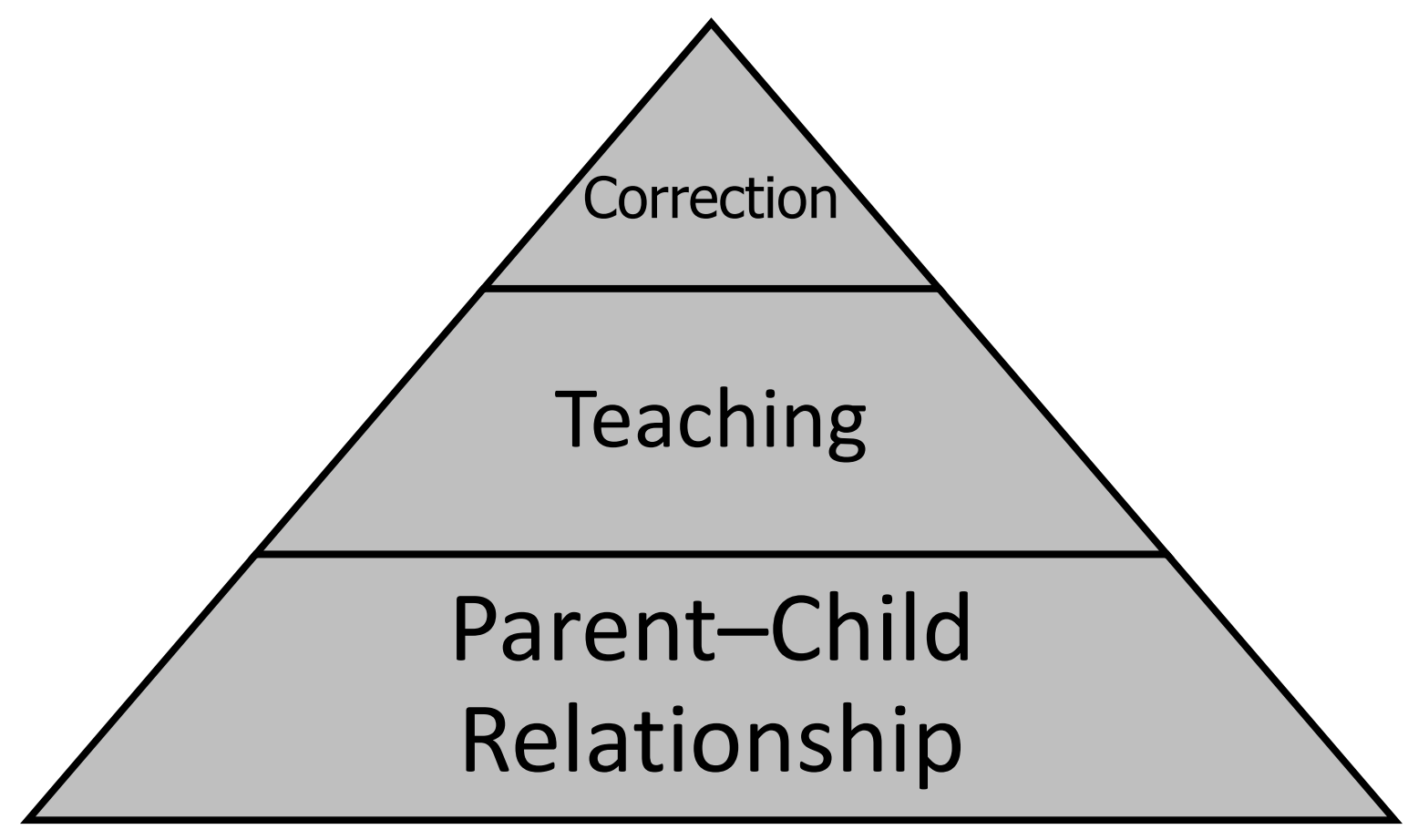

Figure 1. The parenting pyramid. Adapted from the Arbinger Institute (1998). 